\title{
Operando analysis of lithium profiles in Li-ion batteries using nuclear microanalysis
}

S. Surblé ${ }^{a,{ }^{*}}$, C. Paireau ${ }^{a}$, J-F. Martin ${ }^{b}$, V. Tarnopolskiy ${ }^{b}$, M. Gauthier ${ }^{a}$, H. Khodja ${ }^{a}$, L. Daniel ${ }^{b}$, S. Patoux

a LEEL, NIMBE, CEA, CNRS, Université Paris-Saclay, CEA Saclay 91191 Gif-sur-Yvette France b CEA / LITEN / DEHT / L2MB, 17 rue des Martyrs 38054 Grenoble cedex 9, France

\section{HIGHLIGHT}

- Operando observation of lithium and fluorine concentrations and distributions in lithium-ion battery

- Direct visualization and characterization of the electrode/electrolyte interface

- Elemental characterization of $\mathrm{LiFePO}_{4}$ electrodes

- Development of an in situ or operando electrochemical cell for profiling lithium using Ion Beam Analysis techniques

\begin{abstract}
A wide variety of analytical methods are used for studying the behavior of lithium-ion batteries and particularly the lithium ion distribution in the electrodes. However, the development of in situ / operando techniques proved powerful to understand the mechanisms responsible for the lithium trapping and then the aging phenomenon. Herein, we report the design of an electrochemical cell to profile operando lithium concentration in $\mathrm{LiFePO}_{4}$ electrodes using Ion Beam Analysis techniques. The specificity of the cell resides in its ability to not only provide qualitative information about the elements present but above all to measure quantitatively their content in the electrode at different states of charge of the battery. The nuclear methods give direct information about the degradation of the electrolyte and particularly reveal inhomogeneous distributions of lithium and fluorine along the entire thickness of the electrode. Higher concentrations of fluorine is detected near the electrode/electrolyte interface while a depletion of lithium is observed near the current collector at high states of charge.
\end{abstract}

Keywords : in situ / operando analysis, nuclear microprobe, lithium-ion batteries 


\section{Introduction}

Energy storage will be more essential in the future than it has never been in the past. Lithium-ion technology holds in this area a prominent place on the market for stationary and mobile applications. Nevertheless, its specific capacity and energy density seem to reach their limits and could be insufficient for the long-term. It is first thus essential to understand the aging phenomena in the existing technology in order to improve their electrochemical performance with new electrode / electrolyte materials or to guide future research. Different physical and chemical processes, such as volume changes, phase transitions, side reactions, etc. mainly govern the decrease in performance of a lithium-ion battery. The ageing phenomena are highly complicated to characterize. [1] In situ / operando measurements allow live monitoring of these phenomena that can be directly link with the battery electrochemical performance. Major developments of characterization techniques have taken place in the last decade, particularly in the cell design and the electrochemical setups that are compatible with the applied technique. Hark et al. have reviewed the recent development in in situ methods for lithium-ion battery research. [2] However, the electrochemical community needs more in situ / operando techniques in order to completely understand the aging mechanism involved during the battery operation. Particularly, the development of techniques that enable spatial resolved measurements such as in situ TEM and in situ X-ray tomography are necessary. [3-5]

The Ion Beam Analysis (IBA) techniques are powerful tools to investigate in a non-invasive way the elemental distributions and the composition of a material. To this purpose, the object to be analyzed is probed by a beam of accelerated particles. The interactions of the beam particles with the atoms of the target material induce reaction products (X-rays, $\gamma$-rays, charged particles), having an energy characteristic of the emitting atom, including light ions such as lithium. The IBA techniques are based on the detection and the analysis of these emitted radiations. Depending on the nature of the detector used, several techniques are available. It is then possible to determine atomic concentration from matrix elements (stoichiometry), in one dimension (depth profiles) or two dimensions (elemental maps). Due to the good sensitivity to the whole periodic table, the IBA techniques have a special impact on materials science and solid-state chemistry physics. However, their application to the characterization of lithium-ion batteries is scarcely known and not enough developed. Only few works have been devoted to this topic. 
Tadić et al. [6] were the first to apply IBA techniques to study the gel-polymer interfaces with Li anode and spinel cathode for Li-ion battery. The elemental composition was determined in some intercalation compounds or thin films before and after lithium insertion. [7-9] Several authors have measured the lithium extraction in cathode materials but only by chemical delithiation. [10,11] Recently, Gonzalez-Arrabal et al. showed that the lithium distribution in lithium-ion battery is dependent of electrode thickness. [12,13] Habrioux et al. carried out ex situ experiments on C$\mathrm{LiFePO}_{4}$ electrodes at different state of charge (SOC). [14] All of these works prove the potential of nuclear analysis techniques, especially in studying elemental concentration distributions of each element present in the target with good lateral resolution (in the $\mu \mathrm{m}$ range). More recently, Mima et al. perform in situ measurement using X-rays and $\gamma$-rays emissions.[15] Two dimensional maps of the lithium and the iron distributions were obtained in the $\mathrm{LiFePO}_{4}$ electrode and the interface between the electrode and the liquid electrolyte. However, they only obtained qualitative elemental maps by combining these two IBA-techniques, no information on the whole elements presents in the electrode or at the interface was shown. On the contrary we report here a specific electrochemical cell which maps operando elemental concentration in a lithium-ion battery using micro-lon Beam Analysis. The design of our cell allows the quantitative determination of the content of all elements present in a $\mathrm{LiFePO}_{4}$ electrode upon charging. Especially, the distribution and concentration of light elements such as lithium and fluorine are presented as function of the state of charge of the $\mathrm{LiFePO}_{4}$ electrode.

\section{Experimental section}

\subsection{Materials preparation}

The positive electrode was prepared by coating an Al current collector with a slurry composed of 92 wt.\% of carbon-coated $\mathrm{LiFePO}_{4}\left(\mathrm{C}-\mathrm{LiFePO}_{4}\right), 4$ wt.\% of carbon black and 4 wt.\% of CarboxyMethyl Cellulose (CMC). The negative electrode was obtained by the same process on a Cu collector with graphite as the active material. Celgard®2400 polypropylene, a Viledon polypropylene foil and $1 \mathrm{M}$ $\mathrm{LiPF}_{6}$ dissolved in 1:1 ethylene carbonate / diethylcarbonate (EC/DEC) were respectively used as separator and electrolyte.

\subsection{Experimental procedures}

The experimental setup and the designed electrochemical cell for in situ / operando measurements using ion beam techniques are represented on Fig.1. The experiments were carried 
out at the nuclear microprobe of the CEA - Paris Saclay. [16] The analysis chamber offers a large range of analysis techniques, which are explained in the section 2.2.1. A 4-axis micron-level goniometer provides precise positioning of the samples. Two cameras visualize the sample. The first one is used to get an overview of the sample, while the second is connected to a $400 \times$ confocal optical microscope and gives more precision on the positioning.

\subsubsection{Underlying principle of ion beam techniques}

Depending on which detectors are placed in the analysis chamber, several IBA methods are available to determine simultaneously the elemental depth profiles or maps. The most common method concerns the detection of the energy of backscattered particles: the Rutherford BackScattering (RBS) for the heavy elements or the Particle Enhanced Scattering (PES) for the lightest ones (with the proton beam). Nuclear reactions also occur with light elements, giving rise to the NRA technique (Nuclear Reaction Analysis) which signal adds up to the RBS / PES one. Back-scattering analysis provides the ability to distinguish the atomic masses of elements and their distribution in depth as a function of the detected energy. The others methods are based on the detection of X-rays and $\gamma$-rays emissions (respectively PIXE and PIGE for Particle Induced X-ray or $\gamma$-ray Emission). The PIXE method is directly comparable with electron probe microanalysis (EPMA) with very similar spectra, except that there is negligible primary bremsstrahlung background due to the much higher particle mass. Consequently, trace element analysis using PIXE has a detection limit orders of magnitude lower than what can be attainable by X-rays spectrometry techniques using electron excitation. As for the PIXE method, where each element has a characteristic X-rays energy, the energy of the $\gamma$-emitted during the irradiation is characteristic of one element for the PIGE technique.

Protons beams in the range 1.0 - 4.0 MeV are preferred for lithium and fluorine analysis, as it offers an optimal compromise of probing techniques, listed hereafter:

- Efficient and well-known EBS cross sections of all elements

- Enhanced PIXE cross sections (compared to other projectiles)

- $\quad$ Available NRA and PIGE reactions for both Li and F.

Regarding Li and F measurements, PIGE technique was selected as it produces well separated spectrum contributions (478keV and197 keV $\gamma$-rays from ${ }^{7} \mathrm{Li}\left(\mathrm{p}, \mathrm{p}^{\prime} \gamma\right)^{7} \mathrm{Li}$ and ${ }^{19} \mathrm{~F}\left(\mathrm{p}, \mathrm{p}^{\prime} \gamma\right)^{16} \mathrm{O}$ reactions respectively), while NRA gives rise to very close $\mathrm{Li}$ and $\mathrm{F}$ contributions $(7471.4 \mathrm{keV}$ and $7561.4 \mathrm{keV} \alpha$ particles from ${ }^{7} \mathrm{Li}\left(\mathrm{p}, \alpha_{0}\right){ }^{4} \mathrm{He}$ and the ${ }^{19} \mathrm{~F}\left(\mathrm{p}, \alpha_{0}\right){ }^{16} \mathrm{O}$ reactions respectively). Although the RBS and PIXE 
spectra are not directly used for the lithium content determination, these techniques provide information about all elements present on the analyzed target.

\subsubsection{Specific consideration for in situ cell design}

Many groups have designed electrochemical cells for in situ or operando measurements. In situ cells have not a single ideal design. Indeed, each cell needs to fit the experimental setup available for the experiment purpose. In this paper, we present the electrochemical cell that we develop with specific requirements for IBA experiments:

- Being able to cycle electrochemically for ten cycles at different rate of charge (from $\mathrm{C} / 5$ to $\mathrm{C} / 100)$

- Being airtight. IBA techniques are generally performed under vacuum while the charge / discharge of a Li-ion battery is achieved under inert atmosphere.

- Taking account of the geometric space of the analysis chamber.

- Providing a good quality of IBA spectra in 30 minutes or less with no contributions apart from those of the electrodes / electrolyte materials.

To conduct ion beam measurements on an operating battery, a transparent window needs to be incorporated to the design in order to allow the ion beam to reach the electrode(s) / electrolyte under investigation. Since the interaction between the beam and the window can induce an undesirable background, the exit window must fulfill the following conditions: (i) minimum of energy loss and energy straggling; (ii) minimum of interfering signal; (iii) good resistance to pressure and irradiation. As silicon nitride windows are commonly used to extract ion beam to air, we choose for our electrochemical cell a $200 \mathrm{~nm} \mathrm{Si} \mathrm{N}_{4}$ window.

The analysis chamber is usually equipped with three detectors, recording simultaneously the backscattered particles, X-ray and $\gamma$-ray emissions. We choose to exploit with our electrochemical cell the backscattered particles (RBS) and the $\gamma$-ray emissions (PIGE) as explained in section 2.2.1. In the present work, the measurements with the nuclear microprobe have been performed using a $3 \times 3 \mu \mathrm{m}^{2}$ proton beam of $2.6 \mathrm{MeV}$. The battery is assembled inside a glove-box using the order described in Fig. 1. Stainless steel discs and spring ensured pressure in the system and good electrical contact between the battery components.

\section{Results and discussion}

3.1. Preliminary tests 
A series of tests were made for evaluating the cell and the reliability of the electrochemical data.

Fig. 2 shows the cycling performance at $\mathrm{C} / 10$ rate between $2.5 \mathrm{~V}$ and $3.8 \mathrm{~V}$ for the $\mathrm{LiFePO}_{4} / \mathrm{Graphite}$ battery assembled in a Swagelok cell and in the in situ electrochemical cell. The initial capacity is similar (near $140 \mathrm{~mA} \cdot \mathrm{h} . \mathrm{g}^{-1}$ ) in both setups (using a different quantity of electrolyte) but the polarization is higher with the in situ cell. The irreversible capacity is identical for the battery cycled with few drops of electrolyte for the first cycle. The higher capacity fading of the in situ cell, observed after 10 cycles, is ascribed to a loss of pressure and electrical contact between electrodes and current collectors in the cell. The electrochemical cell designed to perform in situ or operando nuclear experiments delivers electrochemical performances comparable to those obtained with classical electrochemical cells on the first two cycles.

\subsection{Lithium and fluorine profiles}

Elemental or full concentration maps can be drawn from specific region of interest. As shown in Fig. 3, each component of the battery are clearly identified in the map drawn from the RBS spectrum (1000-3000 keV).

Fig. 4 shows typical RBS and PIGE spectra corresponding to the region of the $\mathrm{LiFePO}_{4}$ material / electrolyte in the in situ cell. RBS technique is based on the fact that the energy of a backscattered particle depends both on the mass of the target atom (kinematic factor) and the depth at which the scattering took place (energy loss on the way to and from the point of interaction). This allows to profile the elemental composition of the sample close to the surface (see suppl. info. Fig. S1). A RBS spectrum is composed of a succession of narrow peaks for a thin film and steps for a thicker target. In our work, the simulation of the RBS spectra is performed using several layers representing the different elements or components the beam is meeting. The ion beam meets first the $\mathrm{Si}_{3} \mathrm{~N}_{4}$ window, then the argon layer, located in the interspace between the window and the battery, and finally the $\mathrm{LiFePO}_{4}$ electrode. The presence of argon events on the RBS spectrum arises from the gas encapsulated in the in situ cell, as the battery is assembled in an argon glove box to avoid any possible reaction with moisture or air. If a decomposition of the electrode or electrolyte should happen, supplementary layers with others compositions will arised on the spectrum. Following the numbers of observed layers and its thickness, the detected energy for one element is shifted towards lower energy (compared to the surface energy position). 
As described elsewhere [14,17], the fluorine and lithium concentrations are determined in PIGE analysis by comparison with reference samples using the following relation:

$$
\frac{\left[X_{\text {sample }}\right]}{\left[X_{\text {standard }}\right]}=\frac{S_{\text {sample }}}{S_{\text {standard }}} \times \frac{A_{\text {sample }}}{A_{\text {standard }}} \times \frac{N_{\omega \text { standard }}}{N_{\omega \text { sample }}}
$$

where $S$ is the stopping power of the sample, $\mathrm{A}$ the peak area associated with $\gamma$-ray transitions observed for an element $\mathrm{X}(\mathrm{F}$ at $197 \mathrm{keV}$ and $\mathrm{Li}$ at $478 \mathrm{keV})$ and $\mathrm{N}_{\omega}$ the number of protons per solid angle unit delivered to the selected area. The reference samples are respectively $\mathrm{CaF}_{2}$ glass and pristine $\mathrm{LiFePO}_{4}$ electrode. The composition of this electrode is verified using the NIST Silicate Glass Certified Reference Material SRM 610 (428 ppm). Using SIMNRA ${ }^{\circledR}$ software [18], simulations of the RBS spectra as function of the composition of the target give access to the values of $S$ and $N_{\omega}$. The whole process is repeated before reaching a global coherency.

First, only the three layers mentioned above $\left(\mathrm{Si}_{3} \mathrm{~N}_{4}, \mathrm{Ar}\right.$ and electrode) are used for the simulation of the RBS spectra before charging the battery (Fig. 4a). When the charge of the battery occurs, others layers need to be added. The energy of a backscattered particle is now spread over several keV (Fig. 4b). This modification seems to be induced by a degradation of the electrolyte. We note that the regions corresponding to fluorine and phosphorus atoms (respectively near $2122 \mathrm{keV}$ and $2302 \mathrm{keV}$ ), are no more composed of two distinguishing steps but successive narrow steps. Moreover, the Ar signal decreases during the charge. Yoshida et al. [19] have studied the degradation mechanism of alkyl carbonate solvents used in lithium-ion cells during initial charging. The electrolyte degradation produces essentially gases such as $\mathrm{H}_{2}, \mathrm{CH}_{4}, \mathrm{C}_{2} \mathrm{H}_{4}, \mathrm{CO}$ and $\mathrm{CO}_{2}$.[20] The simulation of the RBS spectra is then performed by adding $\mathrm{C}, \mathrm{O}, \mathrm{H}$ and $\mathrm{F}$ in the layer containing the argon. The initial $\mathrm{Ar}$ signal is thus hidden by the presence of other gases. As a result the simulation of the in situ RBS spectra is particularly hard to perform due to the presence of multiple layers and to the permanent change of the electrolyte composition. Although it is not possible to estimate with a good accuracy the full composition of each layer, the stopping power of the last layer (corresponding to the electrode) does not change drastically ( $2-3 \%$ of change), and the concentration of lithium and fluorine can thus be estimated from the PIGE spectra with a good accuracy. In this case, the intensities of the ${ }^{19} \mathrm{~F}\left(\mathrm{p}, \mathrm{p}^{\prime} \gamma\right){ }^{16} \mathrm{O}$ at $197 \mathrm{keV}$ and the ${ }^{7} \mathrm{Li}\left(\mathrm{p}, \mathrm{p}^{\prime} \gamma\right)^{7} \mathrm{Li}$ reaction at $478 \mathrm{keV}$ are directly proportional to the concentration. The lithium content decreases as a function of the state of charge (as expected) while the fluorine content changes randomly (Fig. 4c). 
Fig. 5 displays the composition of the electrode from the current collector to the electrolyte at the PIGE spectra. The composition of the electrode close to the interface of the electrode / liquid electrolyte is not constant during the charge of the battery. Unfortunately, the different contributions of lithium present in the sample (inside the electrode or in the electrolyte) cannot be deciphered using any hypothesis, only the whole elemental lithium concentration and distribution are available.

The lithium and fluorine distributions are extracted from the elemental maps drawn from the $\gamma$-rays at $478 \mathrm{keV}$ and $197 \mathrm{keV}$ respectively. We observe systematically a higher concentration of fluorine near the electrode / electrolyte interface. On the other hand, the lithium distribution as a function of the SOC seems to be smoother along the cross section (from the current collector to the electrolyte interface), suggesting a homogeneous diffusion of lithium throughout the entire thickness of the electrode. However, for the $80 \%$ and $88 \%$ SOC, less lithium is found near the current collector, denoting some lithium diffusion hindrance at the end of charge. The $\mathrm{Li}$ and $\mathrm{F}$ distributions reveal that electrochemical reactions occurs, that forms passivation layer (initial electrode thickness $160 \mu \mathrm{m}$ ).

In order to estimate the ratio of electrode / electrolyte, we use the proportion of the pristine delithiated composite electrode. In all experiments, we scan the beam on selected areas of the sample (from $30 \times 180 \mu \mathrm{m}^{2}$ ). We consider that all iron are included in delithiated electrode and thus do not participate in a passivation layer. We deduce that the analyzed region contains around $92.5 \pm 0.3$ at. $\%$ of electrolyte $\left(\mathrm{LiPF}_{6}\right.$ in $\left.\mathrm{DEC} / \mathrm{EC}\right)$ and degradation products and $5.2 \pm 0.6$ at. \% of delithiated composite electrode (included $\mathrm{FePO}_{4}, \mathrm{CMC}$ and $\mathrm{C}$ fibers). This composition remains in the same order for all analyzed SOCs. Numerous electrochemical or chemical reactions occur during the battery operation due to electrolyte degradation, giving rise to different compounds, leading to the observed. The heterogeneity observed here at the electrode / electrolyte interface through the presence of $\mathrm{C}, \mathrm{O}$, $\mathrm{H}$ and $\mathrm{F}$ in the interspace between the $\mathrm{Si}_{3} \mathrm{~N}_{4}$ layer and the battery is due to the presence of electrolyte and to these electrolyte degradation reactions.

Although few drops of liquid electrolyte are used in the cell and the ion beam analysis is performed essentially on the positive electrode (with small contribution of parts of the current collector and liquid electrolyte), we analyze essentially the electrolyte and its decomposition products. The main problem is that liquid flows in the space between the window and the battery. Using less electrolyte led to a 
short circuit of the battery. The obtained spectra are thus more complicated to exploit, but the results provide valuable information on the lithium distribution.

\section{Conclusion}

We presented operando RBS and PIGE measurements applied to measure the lithium and the fluorine distributions in a lithium-ion cell with a $\mathrm{LiFePO}_{4}$ electrode. To this end, we designed a special electrochemical cell allowing for the first time qualitative and quantitative analysis of all the elements in the electrode using IBA techniques. The cell is able to deliver electrochemical performances comparable to those obtained with classical electrochemical cells on the first two cycles. The elemental maps, drawn using the ${ }^{7} \mathrm{Li}\left(\mathrm{p}, \mathrm{p}^{\prime} \gamma\right)^{7} \mathrm{Li}$ and the ${ }^{19} \mathrm{~F}\left(\mathrm{p}, \mathrm{p}^{\prime} \gamma\right)^{16} \mathrm{O}$ reactions of the PIGE spectra, show an inhomogeneity of their distributions with a higher concentration of fluorine near the electrode/electrolyte interface and a depletion of lithium near the current collector at high state of charge. The use of a liquid electrolyte creates complications for the analyses: electrode contributions to the spectra is only $5 \%$ as the liquid flows in the space between the battery and the $\mathrm{Si}_{3} \mathrm{~N}_{4}$ window, rendering the interpretation of resultsdifficult. The use of solid electrolyte in all solid-state batteries should give more information about the parasite electrochemical reaction (composition and thickness). In summary, we have demonstrated how powerful ion beam techniques can be for investigating the lithium profile in lithium batteries. Interestingly, the distribution of others elements such as sodium or magnesium is also possible using the reaction ${ }^{23} \mathrm{Na}\left(\mathrm{p}, \mathrm{p}^{\prime} \gamma\right)^{23} \mathrm{Na}$ at $439 \mathrm{keV}$ or ${ }^{24} \mathrm{Mg}\left(\mathrm{p}, \mathrm{p}^{\prime} \gamma\right)^{24} \mathrm{Mg}$ at 1368 $\mathrm{keV}[21,22]$ and is believed to be of great interest for studying reaction and degradation mechanisms in $\mathrm{Na}$-ion and $\mathrm{Mg}$-ion batteries.

\section{Acknowledgments}

This work is supported by the NTE (Nouvelles Technologies de l'Energie) program of the CEA. We would like to acknowledge Jim Hoarau for the design of the electrochemical cell and helpful discussions, and Didier Guillier and Yvan Kilisky for accelerator operation.

\section{References}

[1] A. Barré, B. Deguilhem, S. Grolleau, M. Gérard, F. Suard, D. Riu, A review on lithium-ion battery ageing mechanisms and estimations for automotive applications, J. Power Sources. 241 (2013) 680-689.

[2] P.P.R.M.L. Harks, F.M. Mulder, P.H.L. Notten, In situ methods for Li-ion battery research: A review of recent developments, J. Power Sources. 288 (2015) 92-105. 
[3] F. Sun, H. Markötter, K. Dong, I. Manke, A. Hilger, N. Kardjilov, J. Banhart, Investigation of failure mechanisms in silicon based half cells during the first cycle by micro X-ray tomography and radiography, J. Power Sources. 321 (2016) 174-184.

[4] C.-Y. Chen, T. Sano, T. Tsuda, K. Ui, Y. Oshima, M. Yamagata, M. Ishikawa, M. Haruta, T. Doi, M. Inaba, S. Kuwabata, In situ Scanning Electron Microscopy of Silicon Anode Reactions in Lithium-lon Batteries during Charge/Discharge Processes, Sci. Rep. 6 (2016).

[5] C.P. Grey, J.M. Tarascon, Sustainability and in situ monitoring in battery development, Nat. Mater. 16 (2017) 45-56.

[6] T. Tadić, M. Jakšić, Z. Medunić, E. Quartarone, P. Mustarelli, Microbeam studies of gel-polymer interfaces with $\mathrm{Li}$ anode and spinel cathode for $\mathrm{Li}$ ion battery applications using PIGE and PIXE spectroscopy, Nucl. Instrum. Methods Phys. Res. Sect. B Beam Interact. Mater. At. 181 (2001) 404-407.

[7] P. Berger, S. Pruvost, C. Hérold, P. Lagrange, Proton enhanced scattering and nuclear reaction analysis microcharacterization of ternary graphite-lithium-calcium intercalation compounds, Nucl. Instrum. Methods Phys. Res. Sect. B Beam Interact. Mater. At. 219-220 (2004) 1005-1009.

[8] J. Światowska-Mrowiecka, S. de Diesbach, V. Maurice, S. Zanna, L. Klein, E. Briand, I. Vickridge, P. Marcus, Li-Ion Intercalation in Thermal Oxide Thin Films of MoO3 as Studied by XPS, RBS, and NRA, J Phys Chem C. 112 (2008) 1105011058.

[9] M.V. Reddy, B. Pecquenard, P. Vinatier, C. Wannek, A. Levasseur, P. Moretto, RBS and NRA analyses of lithium inserted amorphous Li1+xNiVO4 films, Nucl Instr Meth B. 246 (2006) 397401.

[10] E. Andrade, A. Romero Núñez, A. Ibarra Palos, J. Cruz, M.F. Rocha, C. Solis, O.G. de Lucio, E.P. Zavala, Ion beam analysis of partial lithium extraction of LiMn2O4 by chemical delithiation, Nucl. Instrum. Methods Phys. Res. Sect. B Beam Interact. Mater. At. 269 (2011) 440-443.

[11] M. Lachal, R. Bouchet, A. Boulineau, S. Surblé, C. Rossignol, F. Alloin, S. Obbade, Remarkable impact of grains boundaries on the chemical delithiation kinetics of LiFePO4, Solid State Ion. 300 (2017) 187-194.

[12] K. Mima, R. Gonzalez-Arrabal, H. Azuma, A. Yamazaki, C. Okuda, Y. Ukyo, H. Sawada, K. Fujita, Y. Kato, J.M. Perlado, S. Nakai, Li distribution characterization in Li-ion batteries positive electrodes containing LixNi0.8Co0.15Al0.05O2 secondary particles $(0.75 \leqslant x \leqslant 1.0)$, Nucl. Instrum. Methods Phys. Res. Sect. B Beam Interact. Mater. At. 290 (2012) 79-84.

[13] R. Gonzalez-Arrabal, M. Panizo-Laiz, K. Fujita, K. Mima, A. Yamazaki, T. Kamiya, Y. Orikasa, Y. Uchimoto, H. Sawada, C. Okuda, Y. Kato, J.M. Perlado, Meso-scale characterization of lithium distribution in lithium-ion batteries using ion beam analysis techniques, J. Power Sources. 299 (2015) 587-595.

[14] A. Habrioux, S. Surblé, P. Berger, H. Khodja, A. D’Affroux, S. Mailley, T. Gutel, S. Patoux, Nuclear microanalysis of lithium dispersion in $\mathrm{LiFePO} 4$ based cathode materials for $\mathrm{Li}$-ion batteries, Nucl. Instrum. Methods Phys. Res. Sect. B Beam Interact. Mater. At. 290 (2012) 13-18.

[15] A. Yamazaki, Y. Orikasa, K. Chen, Y. Uchimoto, T. Kamiya, M. Koka, T. Satoh, K. Mima, Y. Kato, K. Fujita, In-situ measurement of the lithium distribution in Li-ion batteries using micro-IBA techniques, Nucl. Instrum. Methods Phys. Res. Sect. B Beam Interact. Mater. At. 371 (2016) 298302.

[16] H. Khodja, E. Berthoumieux, L. Daudin, J.-P. Gallien, The Pierre Süe Laboratory nuclear microprobe as a multi-disciplinary analysis tool, Nucl. Instrum. Methods Phys. Res. Sect. B Beam Interact. Mater. At. 181 (2001) 83-86.

[17] C. Crépisson, M. Blanchard, H. Bureau, C. Sanloup, A.C. Withers, H. Khodja, S. Surblé, C. Raepsaet, K. Béneut, C. Leroy, P. Giura, E. Balan, Clumped fluoride-hydroxyl defects in forsterite: Implications for the upper-mantle, Earth Planet. Sci. Lett. 390 (2014) 287-295.

[18] M. Mayer, J.L. Duggan, B. Stippec, I.L. Morgan, SIMNRA, a simulation program for the analysis of NRA, RBS and ERDA, in: AIP Conf. Proc., AIP, 1999: pp. 541-544.

[19] H. Yoshida, T. Fukunaga, T. Hazama, M. Terasaki, M. Mizutani, M. Yamachi, Degradation mechanism of alkyl carbonate solvents used in lithium-ion cells during initial charging, J. Power Sources. 68 (1997) 311-315. 
[20] K. Kumai, H. Miyashiro, Y. Kobayashi, K. Takei, R. Ishikawa, Gas generation mechanism due to electrolyte decomposition in commercial lithium-ion cell, J. Power Sources. 81-82 (1999) 715719.

[21] M. Roberge, H. Bureau, N. Bolfan-Casanova, D.J. Frost, C. Raepsaet, S. Surble, H. Khodja, A.-L. Auzende, G. Fiquet, Is the transition zone a deep reservoir for fluorine?, Earth Planet. Sci. Lett. 429 (2015) 25-32.

[22] G.L.N. Reddy, S. Kumar, S.V. Kumar, J.V. Ramana, S. Veena, V.S. Raju, Depth profiling of Mg by $2010 \mathrm{keV}$ resonance of $24 \mathrm{Mg}\left(\mathrm{p}, \mathrm{p}^{\prime} \mathrm{y}\right) 24 \mathrm{Mg}$ nuclear reaction, Nucl. Instrum. Methods Phys. Res. Sect. B Beam Interact. Mater. At. 266 (2008) 3281-3289. 


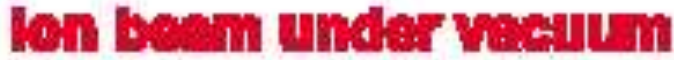
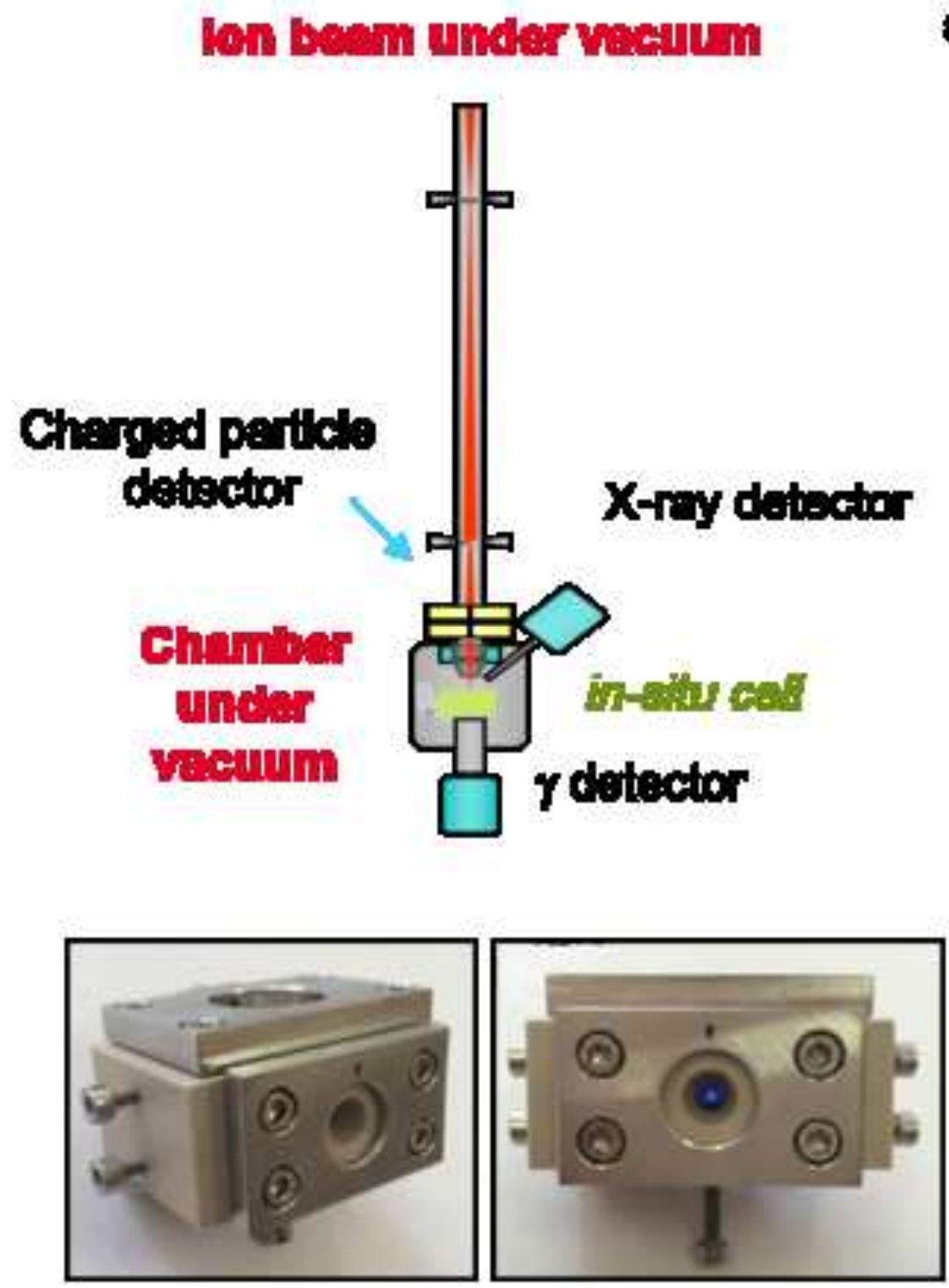

dalnlese stest dlsc (0.5mm)

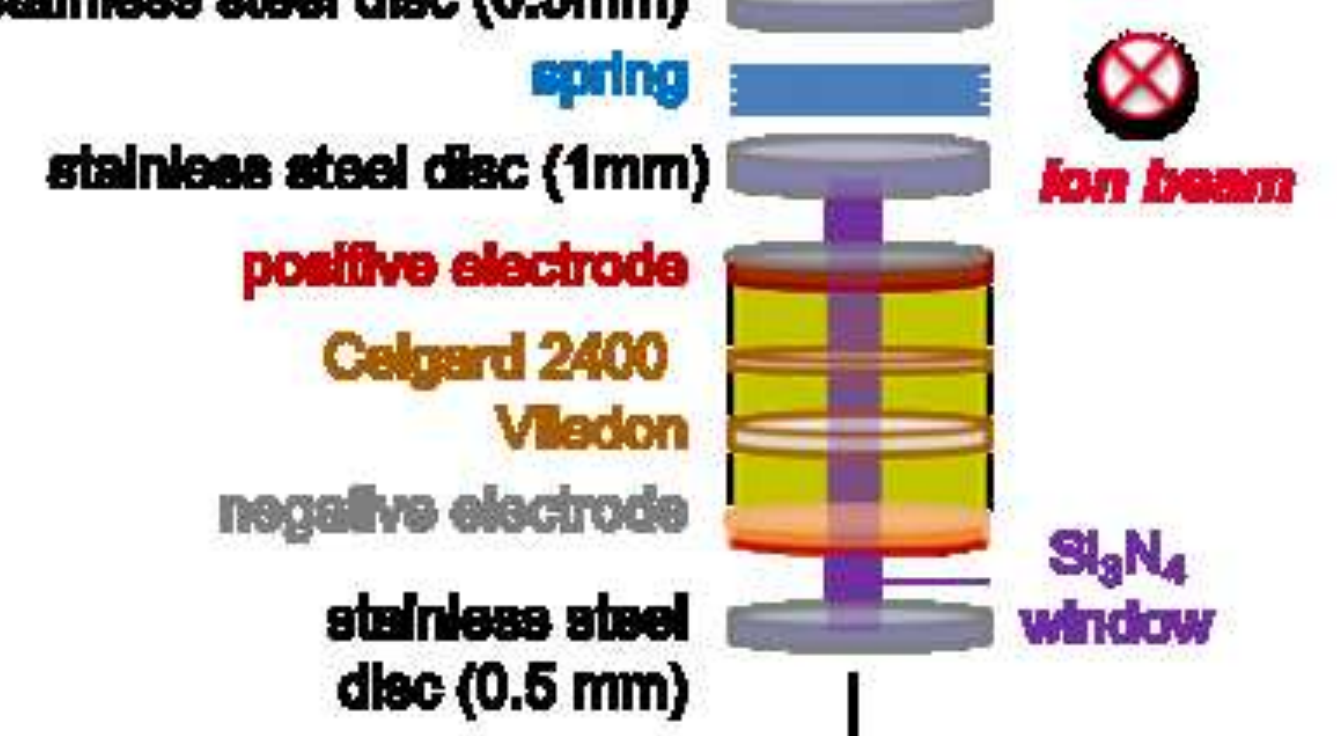

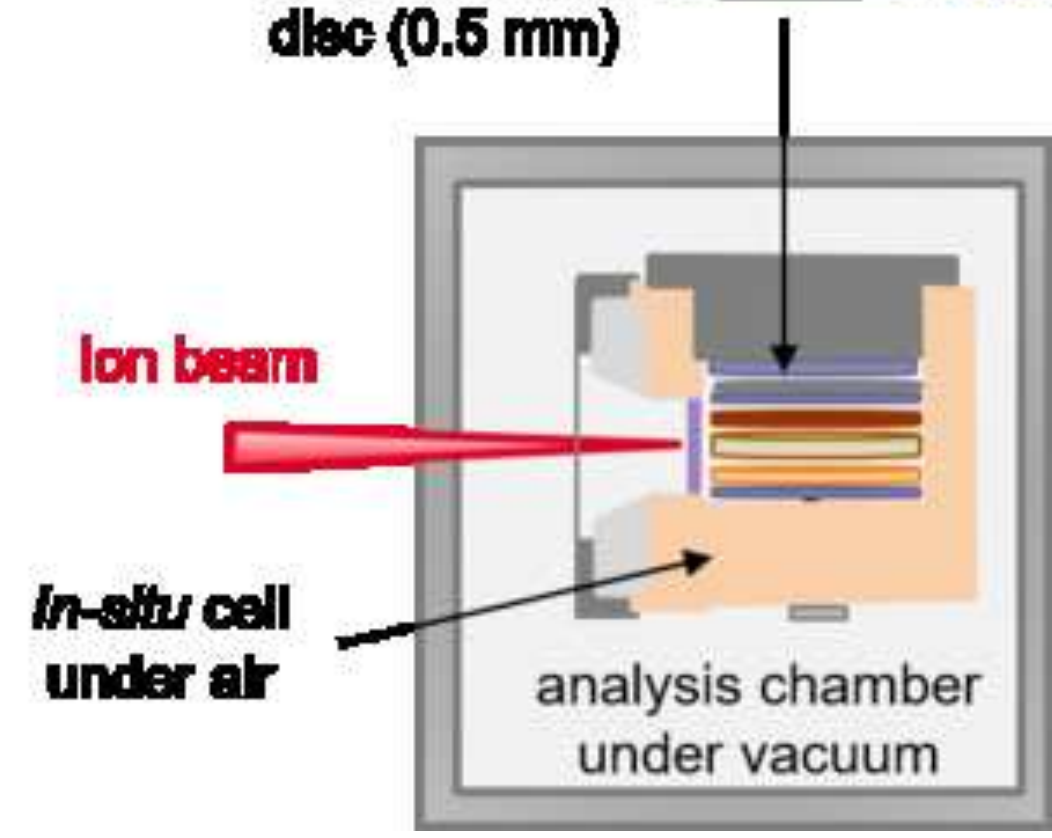




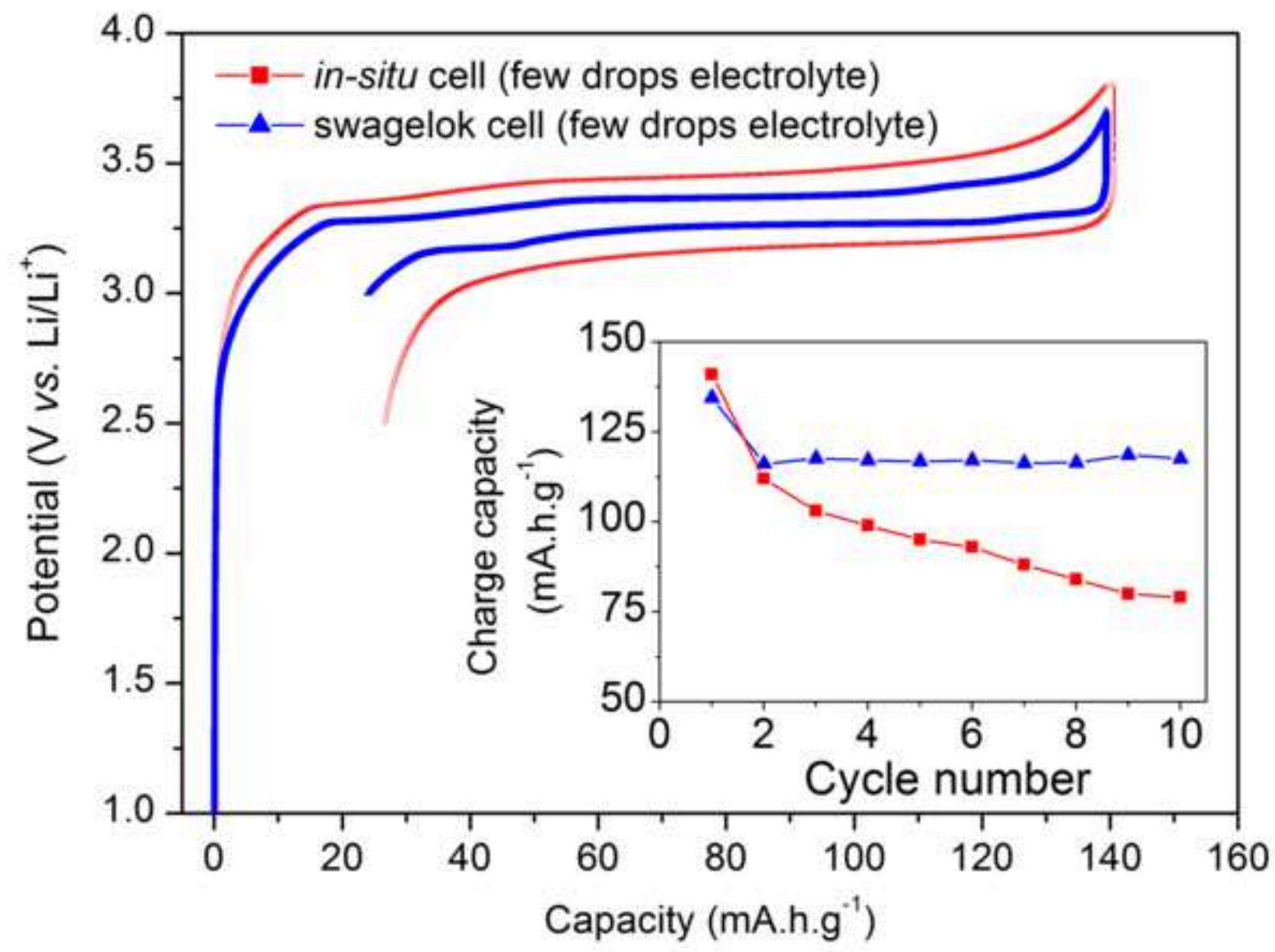




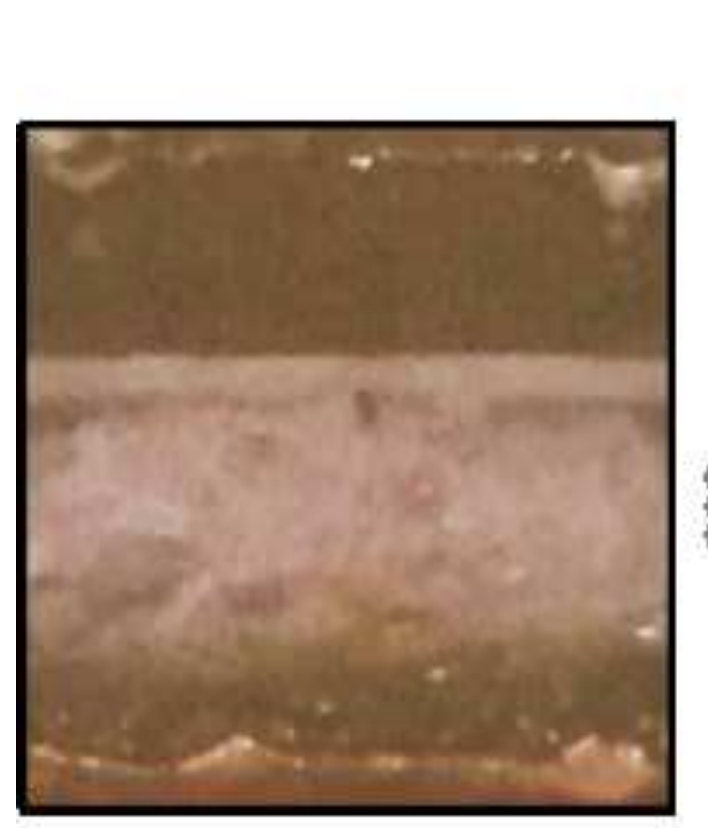

battery plcture
$74 \mu \mathrm{m}$

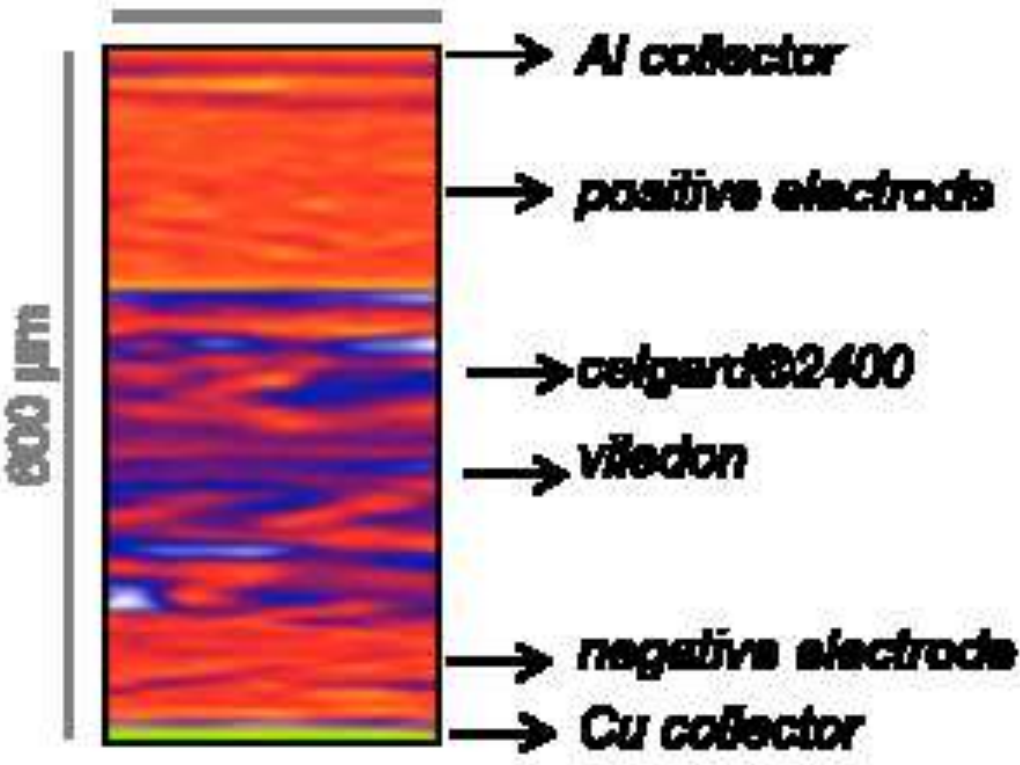

RBS map

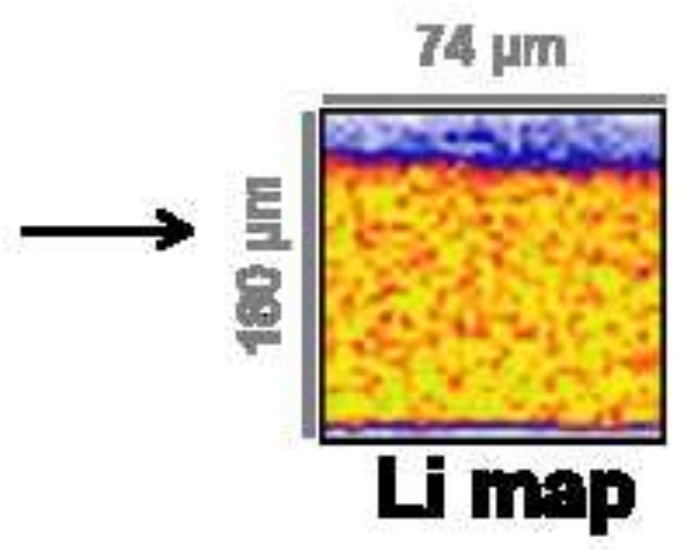

low 


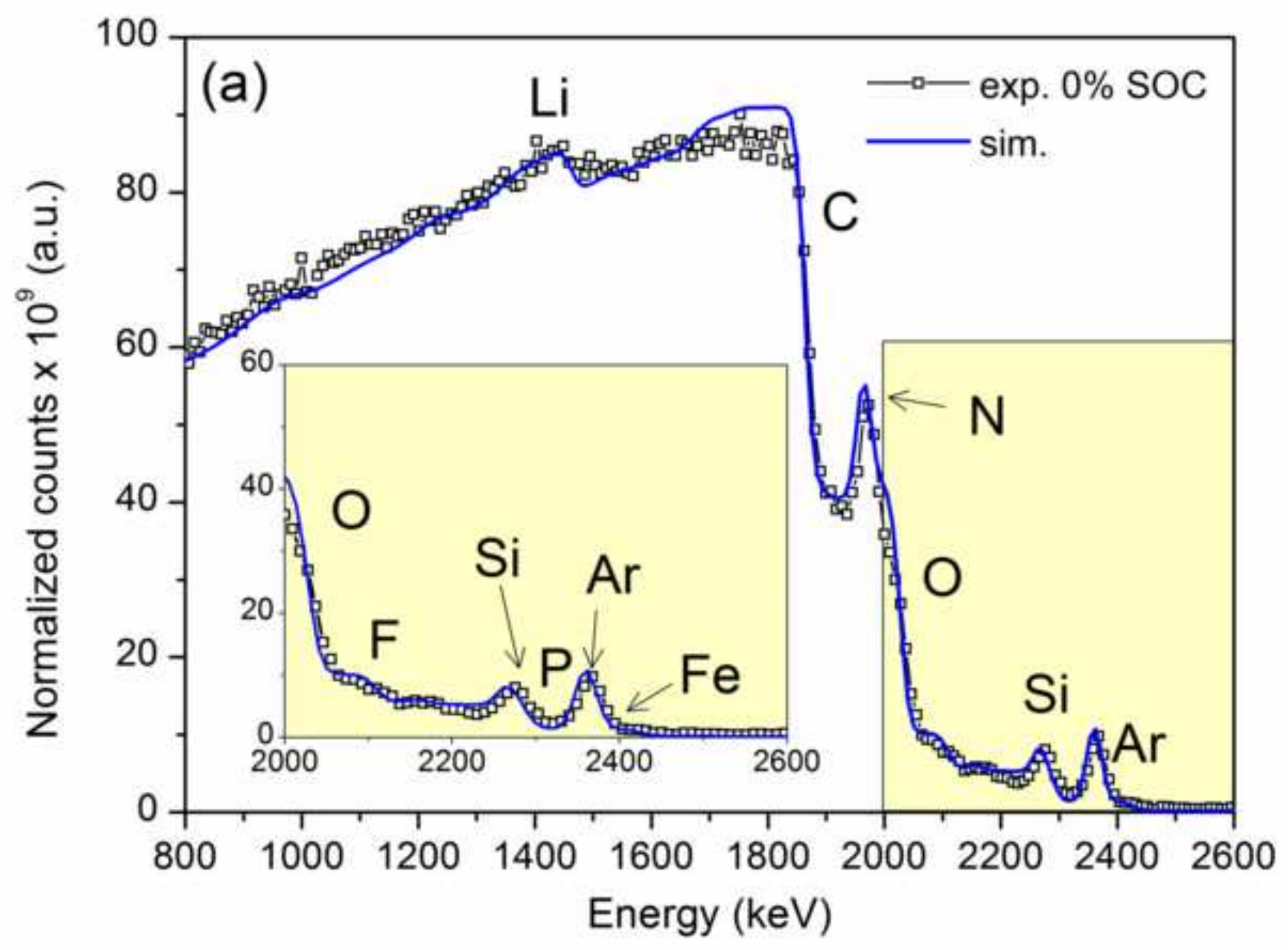




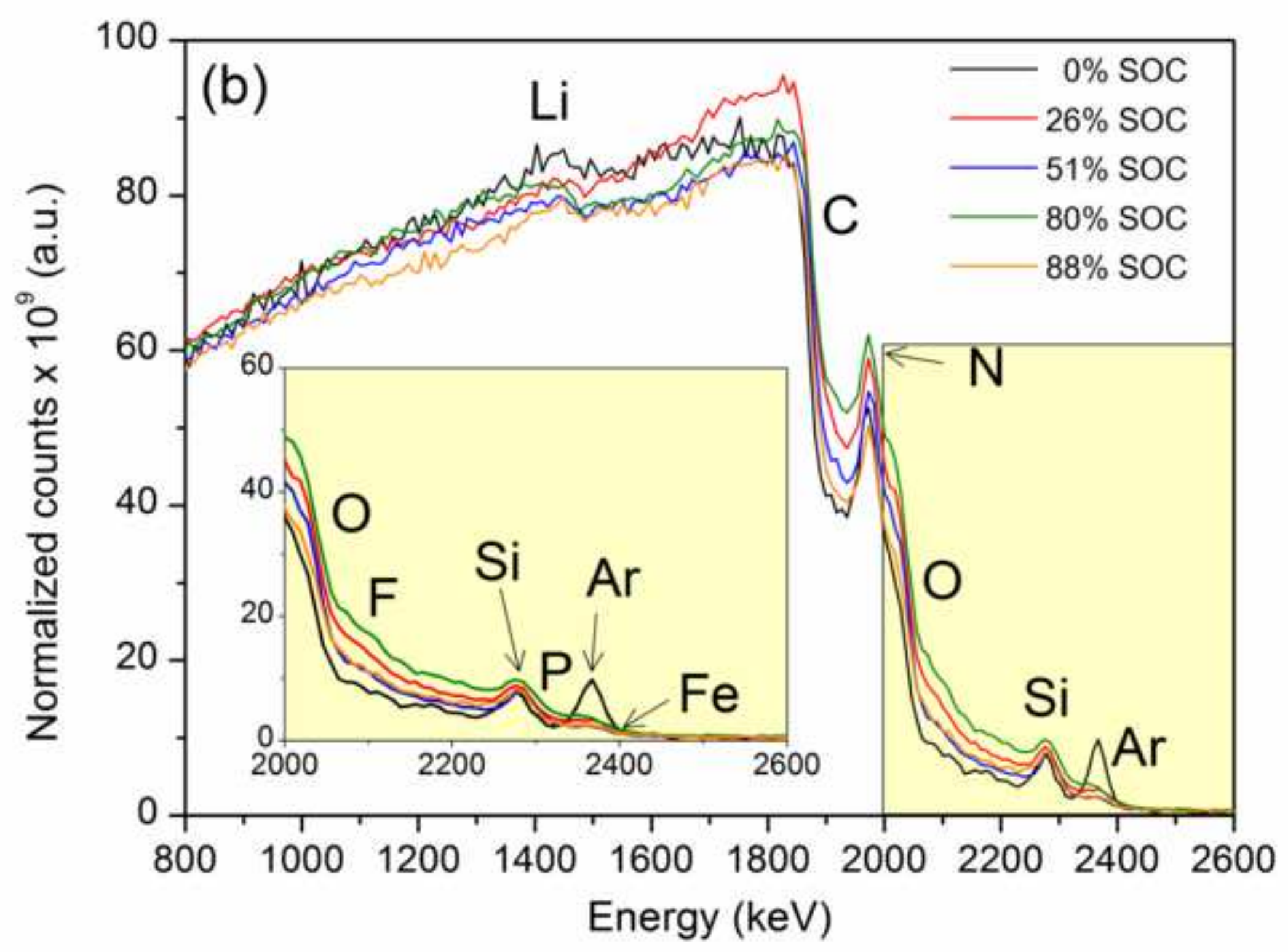




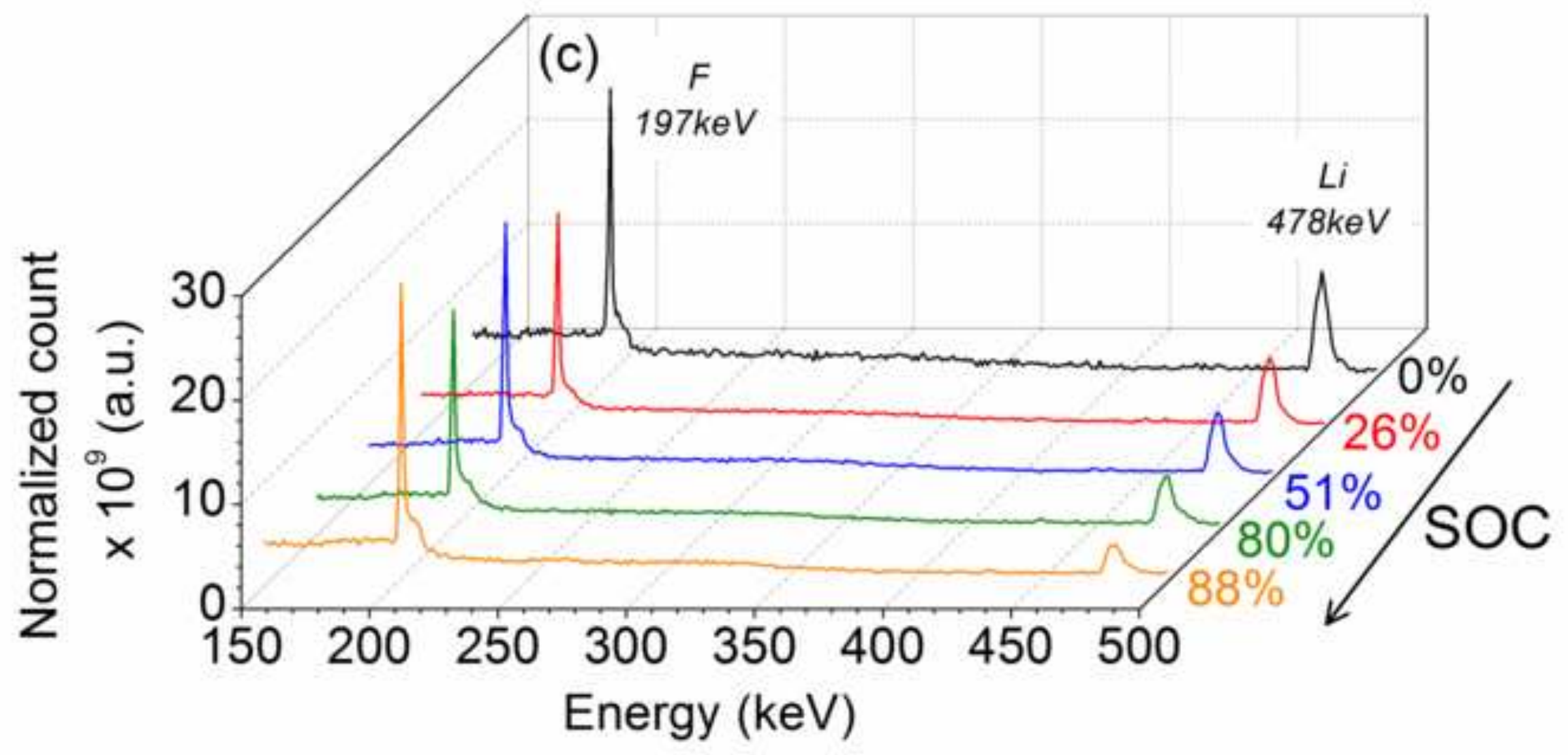




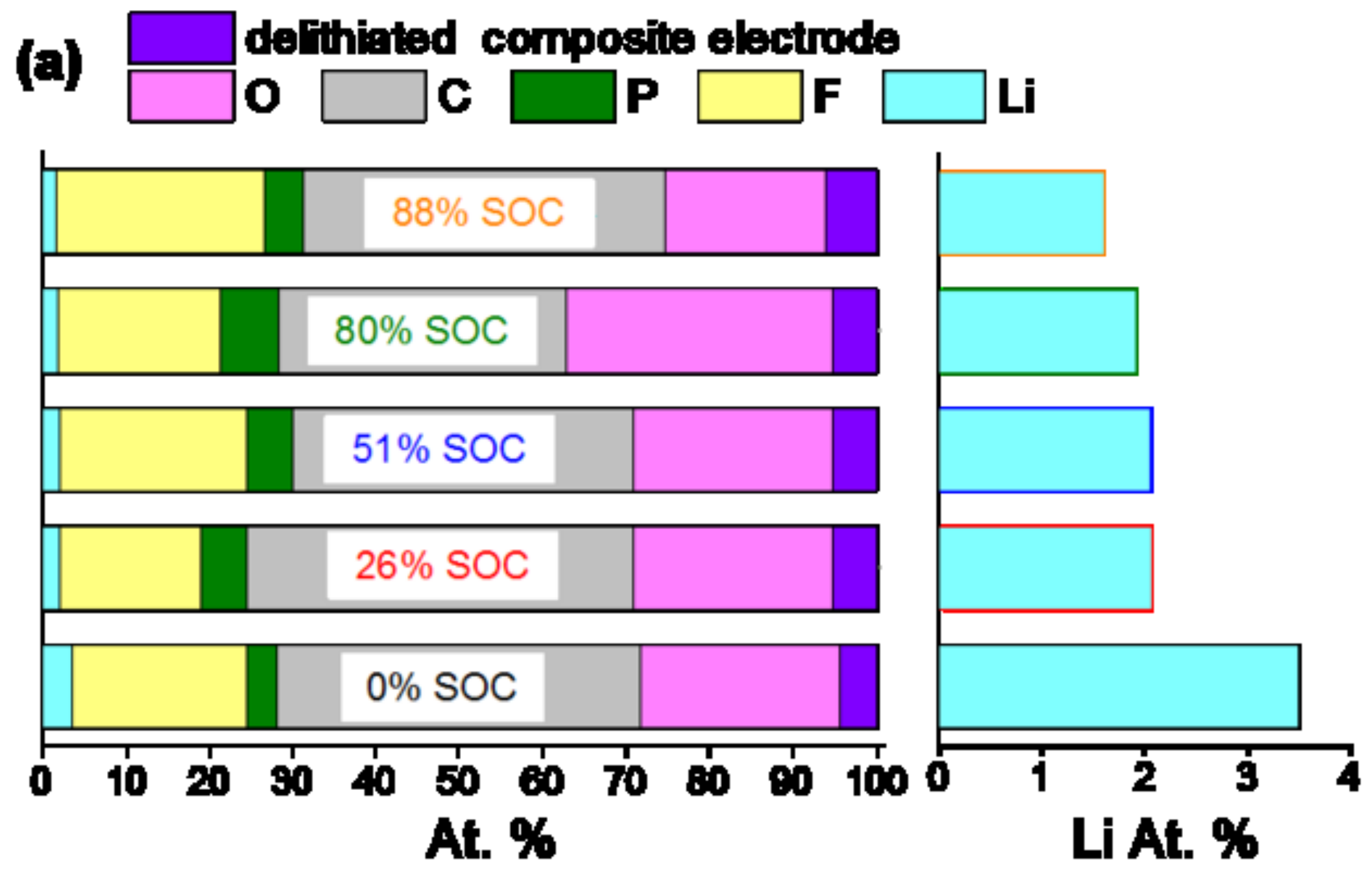


(b)

Li maps
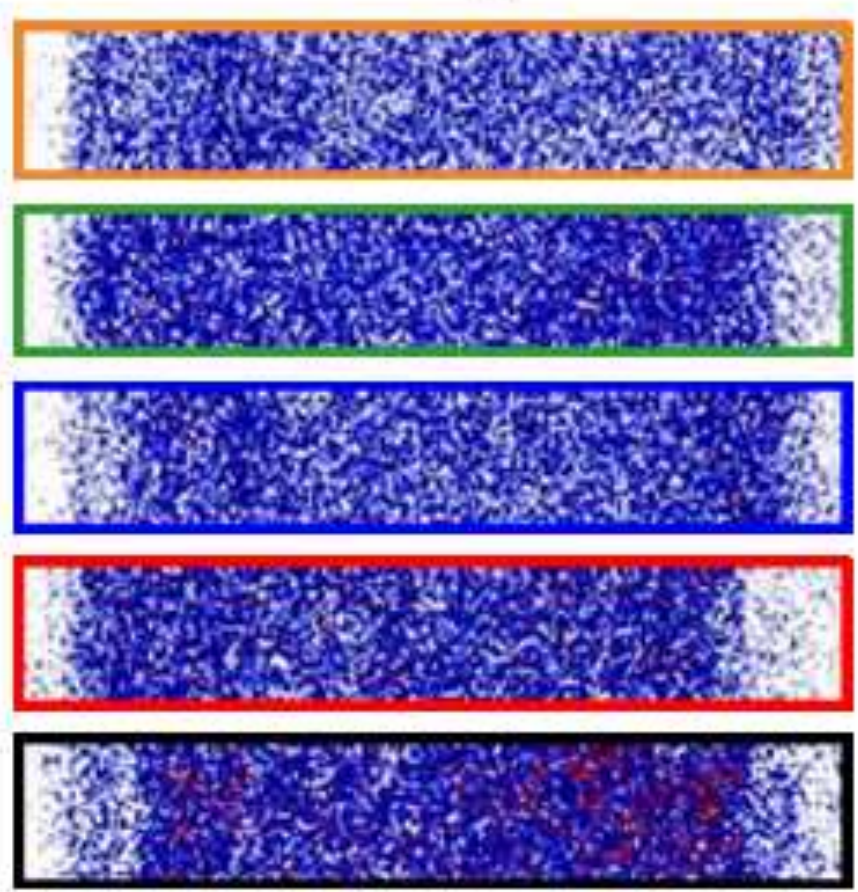

A collector $\longrightarrow$ Electrolyto
$88 \% \mathrm{soc}$

$80 \% 50 \mathrm{C}$

$51 \% 50 \mathrm{C}$

$26 \% 50 \mathrm{C}$

\%soc
$50 \mathrm{pm}$

\section{F maps}
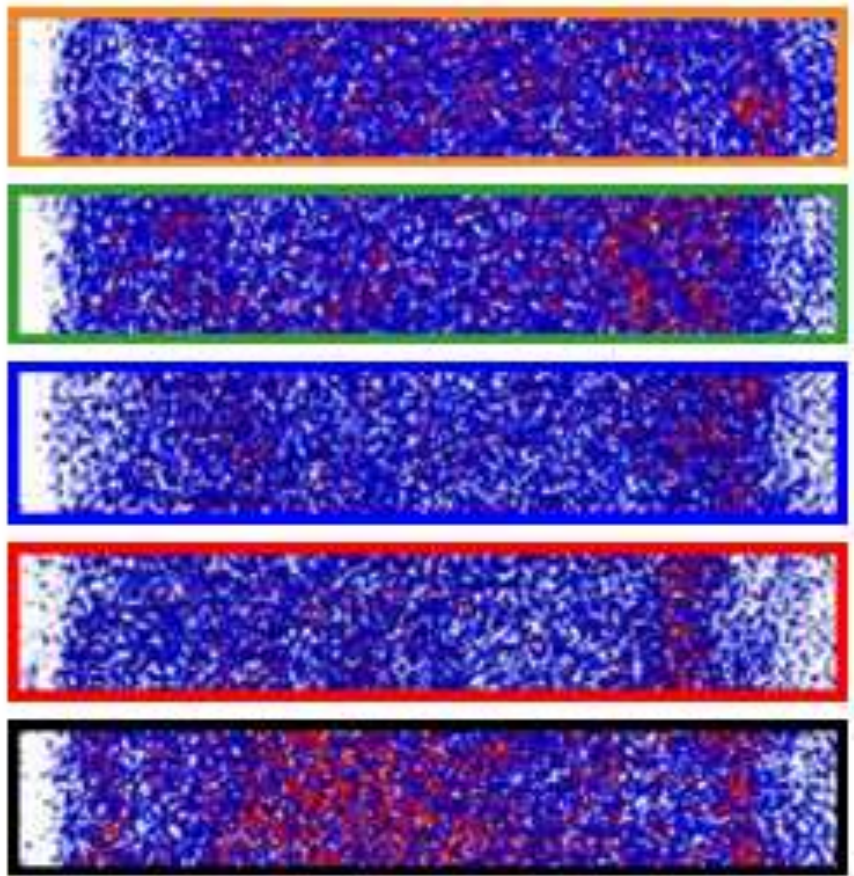

Al collector $\longrightarrow$ Electrolyte 


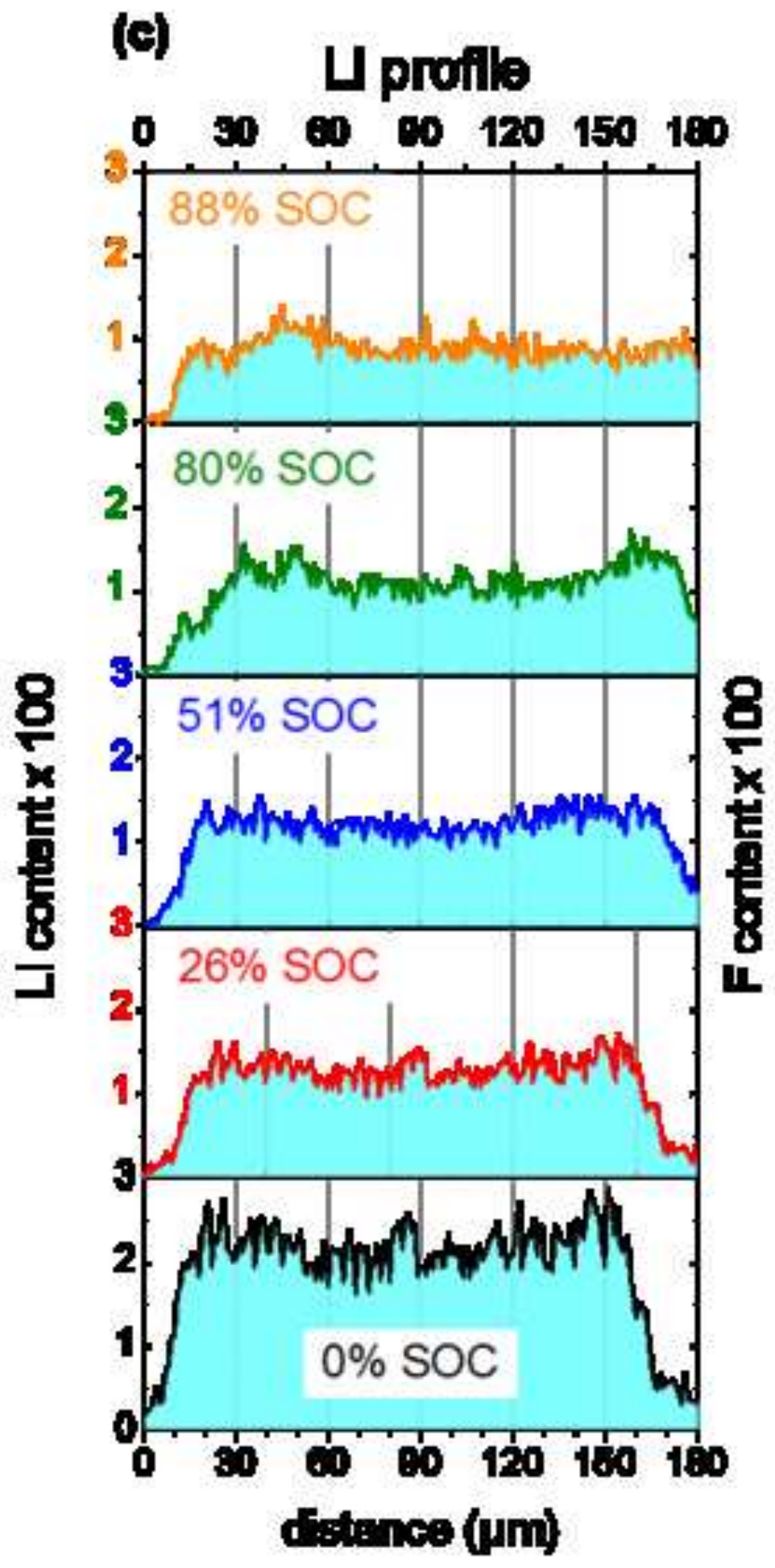

$F$ profile

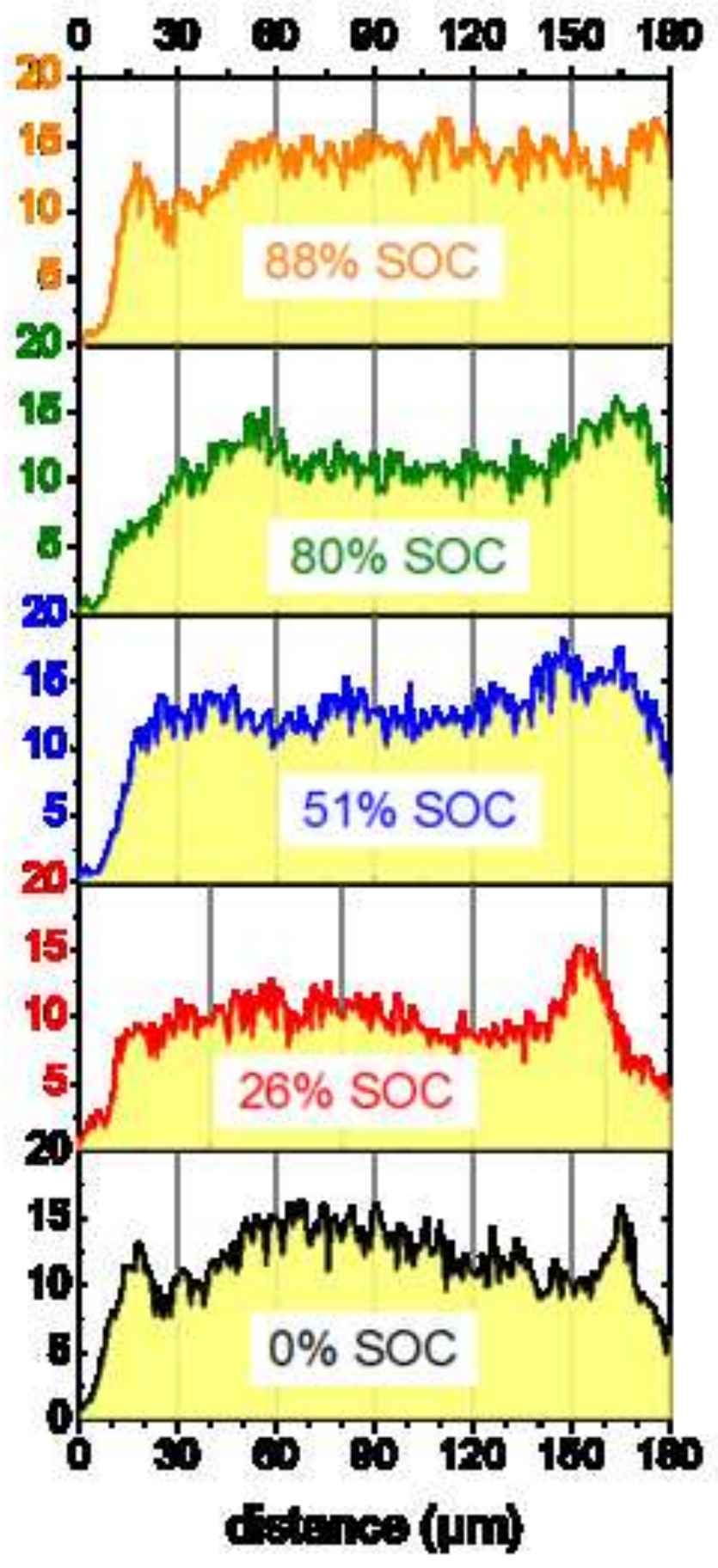




\section{Figure captions}

Fig. 1. Schematic illustrations of the experimental setup and the designed electrochemical cell for ion beam analysis.

Fig. 2. First electrochemical cycle for $\mathrm{LiFePO}_{4} /$ Graphite in Swagelok cell and in situ cell with different quantity of electrolyte. Inset shows the charge capacity vs. cycle number for a full cell assembled either in a Swagelok device or in the in situ cell with a different quantity of electrolyte.

Fig. 3. Identification of each component of the battery on the map drawn from the RBS spectra. The lithium map is drawn from the $7 \mathrm{Li}\left(\mathrm{p}, \mathrm{p}^{\prime} \gamma\right) 7 \mathrm{Li}$ reaction at $478 \mathrm{keV}$ from the PIGE spectrum.

Fig. 4. (a) Example of the simulation of RBS spectrum for a $\mathrm{LiFePO}_{4}$ material in the in situ cell before charging. (b) and (c) Evolution of the RBS and PIGE spectra of electrode / electrolyte region during the charge of the in situ cell at $\mathrm{C} / 75$ rate. For the sake of comparison, each spectrum is normalized by the number of incident particles.

Fig. 5. (a) Elemental composition obtained using nuclear microanalysis in the cross section of the $\mathrm{LiFePO}_{4}$ electrode (from the Al collector to the electrolyte). The composition of delithiated composite electrode is estimated from the proportion of the pristine delithiated composite electrode. (b-c) Lithium and fluorine maps drawn from the $\gamma$-rays at $478 \mathrm{keV}$ and $197 \mathrm{keV}$ respectively and theirs distributions along the electrode depth (the left side of the map corresponds to the electrode on the Al collector: $d=0 \mu \mathrm{m}$, and the right side to the separator: $d=180 \mu \mathrm{m})$ as a function of the state of charge (SOC). 